Computer Applications: An International Journal (CAIJ), Vol.2, No.1, February 2015

\title{
Blood Donation System For Online Users
}

\author{
San San Tint ${ }^{1}$ and Htoi Mai ${ }^{2}$ \\ ${ }^{1}$ Department of Research and Development II, University of Computer Studies, \\ Mandalay, Myanmar \\ ${ }^{2}$ Master of Computer Science, University of computer Studies Mandalay, Myanmar
}

\begin{abstract}
Most of people desire to know about online blood donation to the patients at once. Patients want to get blood to live at emergency time. At present people are needed to know how to contact blood donors online. This system provides how to get blood at their serious time to be longer life time. Matcher system is implemented with Decision Tree and Decision Table by rules. This matcher applies the rules based on Blood Donation in Blood Bank in Myanmar. Information about donors and patients has been reserved in the system so that it is ready to donate blood instantly.
\end{abstract}

\section{Keywords}

Decision, Major, Matcher, Minor, Patient

\section{Introduction}

The development of a Blood Donation System depends on web-based application. System has web-based matcher which acts as server to match donors and patient pair compatibly by using rule-based knowledge. All Clinic System should have patient and donor information control matcher system. Nowadays, computers are the most useful for all fields; they can also stand for information distributing, catching, matching, etc. All doctors who are system's members can see donors' and patients' data and matching information. The health systems using web based application were aided human beings. In this system, blood matcher can help donors' and patients' to get the best matcher.

The establishment of web-based matcher for blood donation system is to encourage blood donor society. Current knowledge applications mainly focus on the discovery, creation, preservation, sharing and direct use of information. Web-based matcher is Web-based application by using knowledge rules, will help the cost of living and saving lives.

\section{Background Theory}

\subsection{Web-based Application}

A web application is any application that uses a web browser as a client. Web based applications make effectiveness for our organization to take good profit. Opportunities come up from Web based application that can be accessed the information from anywhere in the world. It is also providing user to save time and money and making the interactivity better with customers and partners. It permits the administrative plan for staff to be better working from any location. Moreover, users can find to meet their purposes in time and they proceed ultimate aims without wasting valuable things like energy, time, even clothes. 


\subsection{Rule-based Knowledge}

Methods frequently used for knowledge representation are: Rule-based Knowledge, Frame-based Knowledge, Semantic Network, Logic theory and Ontology theory. All of these, Rule-based Knowledge is the most usual use expressive method. Rules are used to support decision making in classification, regression and association tasks. Different types of rules are used to express different types of knowledge [1] [2] [3].

There are many types of rules as following:

○ Classical prepositional logic rules (C-rules),

- Association rules (A-rules),

- Fuzzy logic rules (F-rules),

- M-of-N or threshold rules (T-rules),

- Similarity or prototype-based rules (P-rules).

\subsection{Decision Branch for Tree}

Decision points typically have two or three branches [5]. At the ends of the branches are the outcomes of the decision process. The branch arrangement of a decision tree is as below.

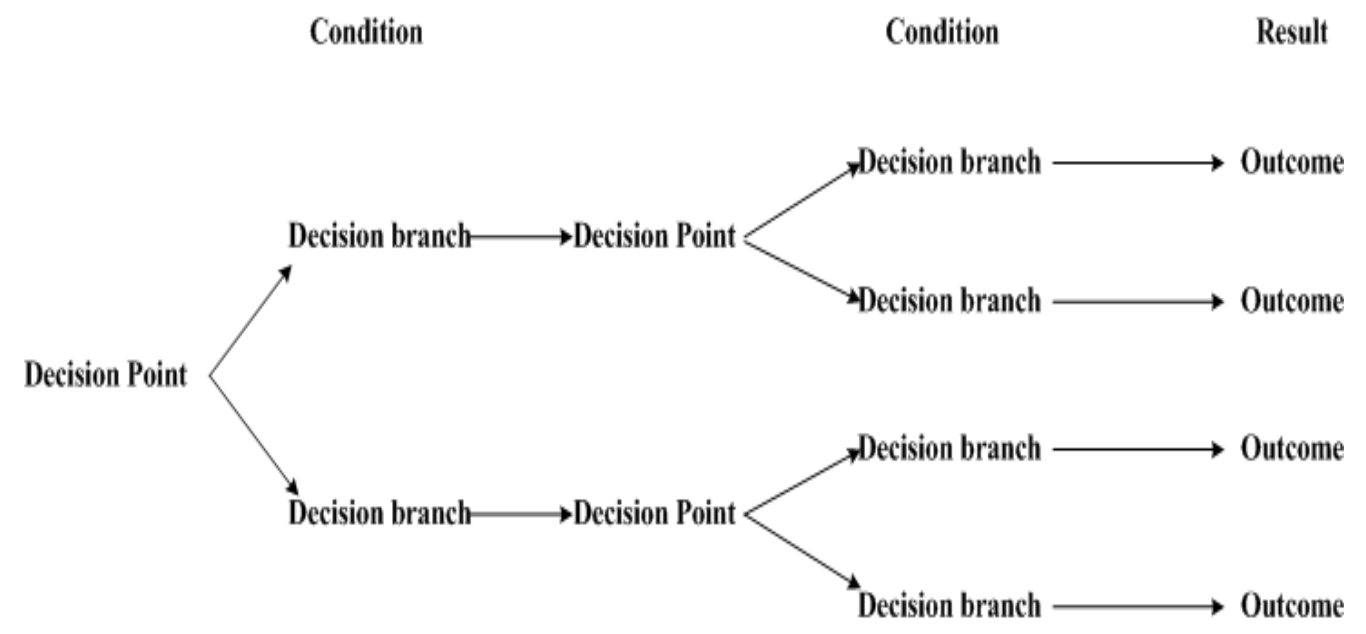

Figure 1. General Branch Arrangement of Decision Tree

\subsection{Decision Tree Classifier for C Rule}

In general expressive power of C-rules is limited. Three other types of rules are fuzzy, threshold and prototype-based rules. Decision trees represent rules in a hierarchical structure with each path/branch giving single rule. Algorithms that simplify such rules converting it into logical rules are known, for example the $\mathrm{C} 4$ rules for the $\mathrm{C} 4.5$ decision trees [1] [6].

\subsection{Decision Table for System}

A decision table is a non-graphical way of representing the steps involved in making a decision [7]. 
Computer Applications: An International Journal (CAIJ), Vol.2, No.1, February 2015

\begin{tabular}{|l||l|}
\hline Issue area & \multicolumn{2}{|l|}{ SYSTEM CONDITION SPACE } \\
\hline SYSTEM CONDITION SET & SYSTEM ACTION SPACE \\
\hline \hline SYSTEM ACTION SET &
\end{tabular}

Figure 2. General Flow of a System's Decision Table

The decision table is divided into three main areas:

- System's Conditions

- System's Actions

- System's Rules

\subsubsection{Decision Table Development for Example}

There are five stages may be distinguished.

○ Definition of conditions, condition states, actions and action states for the specific choice issue;

O Specification of the issue in terms of decision rules;

○ Building of the decision table on the basis of the decision rules;

- Check for completeness, contradictions and correctness;

○ Simplification, optimization and depiction of the decision table.

(a) Full table

\begin{tabular}{|l|l|l|l|l|l|l|l|l|}
\hline $\mathrm{C}_{1}$ & \multicolumn{9}{|l}{} & $\mathrm{Y}$ & \multicolumn{1}{l|}{$\mathrm{N}$} & \multicolumn{3}{l|}{} \\
\hline $\mathrm{C}_{2}$ & $\mathrm{Y}$ & $\mathrm{N}$ & $\mathrm{Y}$ & $\mathrm{N}$ & \\
\hline $\mathrm{C}_{3}$ & $\mathrm{Y}$ & $\mathrm{N}$ & $\mathrm{Y}$ & $\mathrm{N}$ & $\mathrm{Y}$ & $\mathrm{N}$ & $\mathrm{Y}$ & $\mathrm{N}$ \\
\hline $\mathrm{A}_{1}$ & $\mathrm{X}$ & - & $\mathrm{X}$ & - & - & - & - & - \\
\hline $\mathrm{A}_{2}$ & - & $\mathrm{X}$ & - & $\mathrm{X}$ & - & $\mathrm{X}$ & - & $\mathrm{X}$ \\
\hline $\mathrm{A}_{3}$ & $\mathrm{X}$ & - & - & - & $\mathrm{X}$ & - & $\mathrm{X}$ & - \\
\hline $\mathrm{R}$ & $\mathrm{R}_{1}$ & $\mathrm{R}_{2}$ & $\mathrm{R}_{3}$ & $\mathrm{R}_{4}$ & $\mathrm{R}_{5}$ & $\mathrm{R}_{6}$ & $\mathrm{R}_{7}$ & $\mathrm{R}_{8}$ \\
\hline
\end{tabular}

(b) Table contraction

\begin{tabular}{|l||l|l|l|l|l|l|}
\hline \multicolumn{1}{|l||}{$\mathrm{C}_{1}$} & \multicolumn{4}{ll}{} & $\mathrm{Y}$ & \multicolumn{1}{l|}{$\mathrm{N}$} \\
\hline $\mathrm{C}_{2}$ & $\mathrm{Y}$ & \multicolumn{1}{l|}{$\mathrm{N}$} & - & \\
\hline $\mathrm{C}_{3}$ & $\mathrm{Y}$ & $\mathrm{N}$ & $\mathrm{Y}$ & $\mathrm{N}$ & $\mathrm{Y}$ & $\mathrm{N}$ \\
\hline $\mathrm{A}_{1}$ & $\mathrm{X}$ & - & $\mathrm{X}$ & - & - & - \\
\hline $\mathrm{A}_{2}$ & - & $\mathrm{X}$ & - & $\mathrm{X}$ & - & $\mathrm{X}$ \\
\hline $\mathrm{A}_{3}$ & $\mathrm{X}$ & - & - & - & $\mathrm{X}$ & - \\
\hline $\mathrm{R}$ & $\mathrm{R}_{1}$ & $\mathrm{R}_{2}$ & $\mathrm{R}_{3}$ & $\mathrm{R}_{4}$ & $\mathrm{R}_{5}$ & $\mathrm{R}_{6}$ \\
\hline
\end{tabular}

(c) Row order optimization

\begin{tabular}{|l||l|l|l|l|}
\hline \multicolumn{1}{|l||}{$\mathrm{C}_{3}$} & \multicolumn{2}{ll}{} & $\mathrm{Y}$ & $\mathrm{N}$ \\
\hline $\mathrm{C}_{1}$ & $\mathrm{Y}$ & $\mathrm{N}$ & - \\
\hline $\mathrm{C}_{2}$ & $\mathrm{Y}$ & $\mathrm{N}$ & - & - \\
\hline \hline $\mathrm{A}_{1}$ & $\mathrm{X}$ & $\mathrm{X}$ & - & - \\
\hline $\mathrm{A}_{2}$ & - & - & - & $\mathrm{X}$ \\
\hline $\mathrm{A}_{3}$ & $\mathrm{X}$ & - & $\mathrm{X}$ & - \\
\hline $\mathrm{R}$ & $\mathrm{R}_{1}$ & $\mathrm{R}_{2}$ & $\mathrm{R}_{3}$ & $\mathrm{R}_{4}$ \\
\hline
\end{tabular}

Figure 3. Optimization of a Decision Table using Two Different Transformations for Example 
Computer Applications: An International Journal (CAIJ), Vol.2, No.1, February 2015

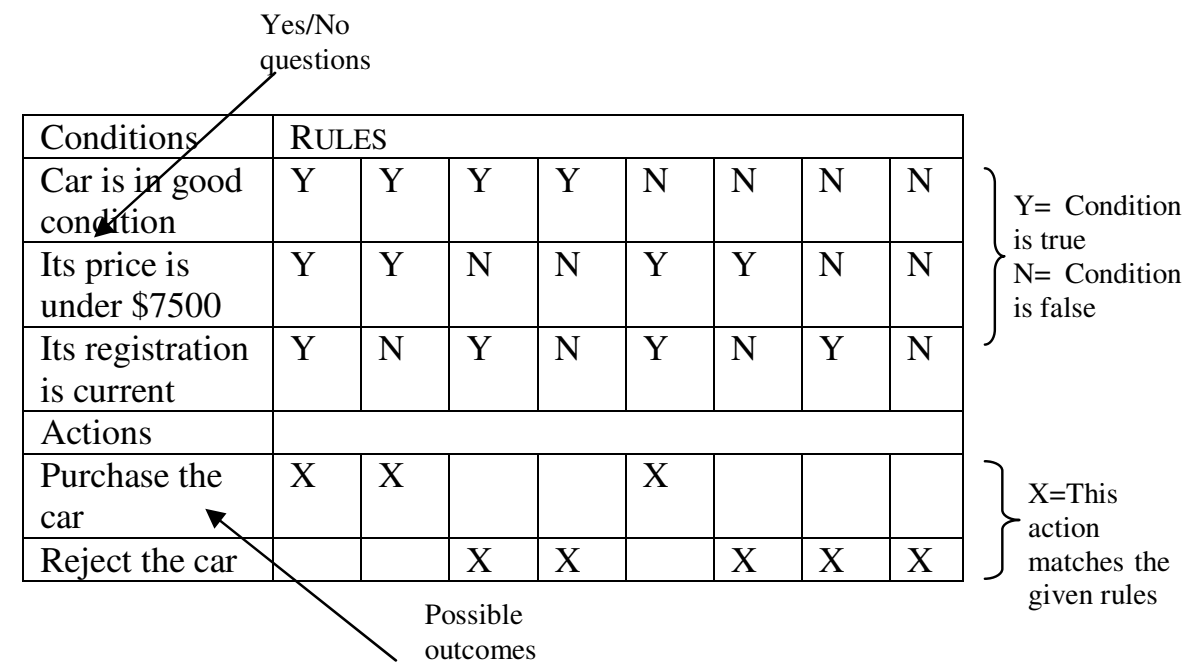

Figure 4. Decision Table for Purchase Car with Conditions for Example

1. Identify conditions and their alternative values.

- Gender's alternative values are: $\mathrm{F}$ and $\mathrm{M}$.

- City dweller's alternative values are: $\mathrm{Y}$ and $\mathrm{N}$.

$\circ$ Age group's alternative values are: A, B, and C.

2. Compute max. number of rules.

- $2 \times 2 \times 3=12$.

- Rule 4 corresponds to M, N, and A. Rule 5 corresponds to F, Y, and B. Rule 6 corresponds to $\mathrm{M}, \mathrm{Y}$, and $\mathrm{B}$ and so on.

3. Identify possible actions

- Market product W, X, Y, or Z.

4. Match each of the actions to take given each rule.

Table 1. Decision Table with Possible Actions

\begin{tabular}{|l|l|l|l|l|l|l|l|l|l|l|l|l|}
\hline & 1 & 2 & 3 & 4 & 5 & 6 & 7 & 8 & 9 & 10 & 11 & 12 \\
\hline Gender & F & M & F & M & F & M & F & M & F & M & F & M \\
\hline City & Y & Y & N & N & Y & Y & N & N & Y & Y & N & N \\
\hline Age & A & A & A & A & B & B & B & B & C & C & C & C \\
\hline MarketW & X & & & & X & & & & X & & & \\
\hline MarketX & X & & X & & & & & & & & & \\
\hline MarketY & & & & & & & & X & & & & \\
\hline MarketZ & $\mathrm{X}$ & $\mathrm{X}$ & $\mathrm{X}$ & $\mathrm{X}$ & $\mathrm{X}$ & $\mathrm{X}$ & $\mathrm{X}$ & $\mathrm{X}$ & & $\mathrm{X}$ & & $\mathrm{X}$ \\
\hline
\end{tabular}


Computer Applications: An International Journal (CAIJ), Vol.2, No.1, February 2015

5. Check that the actions given to each rule are correct.

6. Simplify the table.

- If so, remove those columns.

- In the example scenario, columns 2, 4, 6, 7, 10, and 12 have the same action. For rules 2, 6, and 10; the age group is a "don't care".

Table 2. Decision Table with Optimize Actions

\begin{tabular}{|l|l|l|l|l|l|l|l|l|l|l|}
\hline & 1 & 2 & 3 & 4 & 5 & 6 & 7 & 8 & 9 & 10 \\
\hline Gender & F & M & F & M & F & M & F & M & F & M \\
\hline City & Y & Y & N & N & Y & N & N & Y & N & N \\
\hline Age & A & & A & A & B & B & B & C & C & C \\
\hline MarketW & X & & & & X & & & X & & \\
\hline MarketX & X & & X & & & & & & & \\
\hline MarketY & & & & & & & X & & & \\
\hline MarketZ & X & X & X & X & X & X & X & & & X \\
\hline
\end{tabular}

\section{Our System}

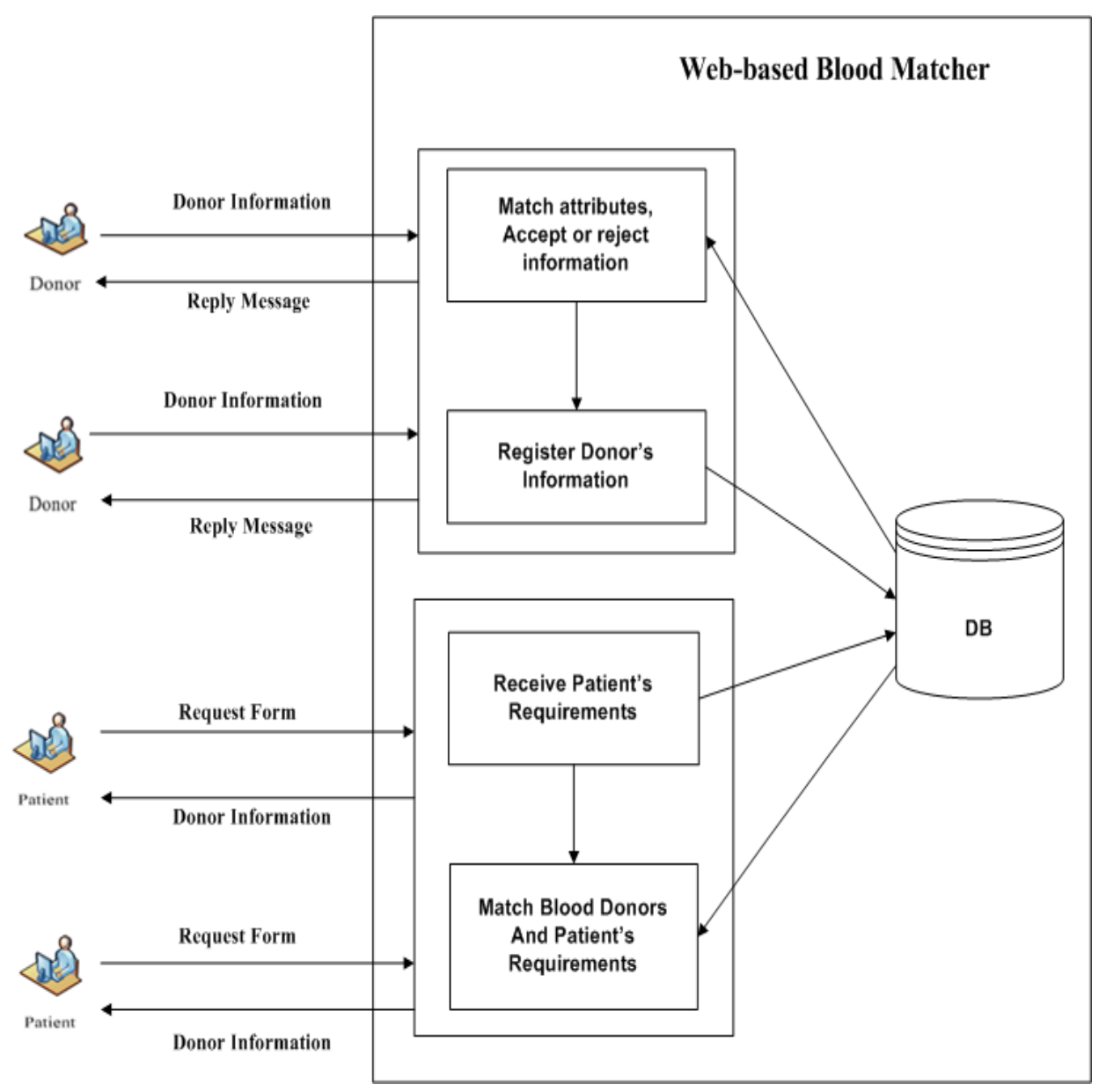

Figure 5. System Architecture of Blood Matcher 
The system is designed to process as follows: two types of users are allowed in this system, the donor type and the patient type. For donor account, as input, the donor needs to enter the information needed for patient to inquire necessary blood. Then the matcher decided to accept the donation of donor or not by using their rules based knowledge.

The architecture for Blood Donation System is as shown in Figure 5. There are three main roles and three main processes. The three main roles are donor, patient and matcher. The three main processes are record the memberships of donors and patients, acquire to get the donor's purification blood and matching the patient with related donors. It needs main database for requirements like specific rules for donors. Main rules are divided into two classes in which man and woman. In donation for blood, specifications for man are not same for woman. The system has three level specifications like major, minor and serious. Patients can search on this page for their needs when they want the blood seriously.

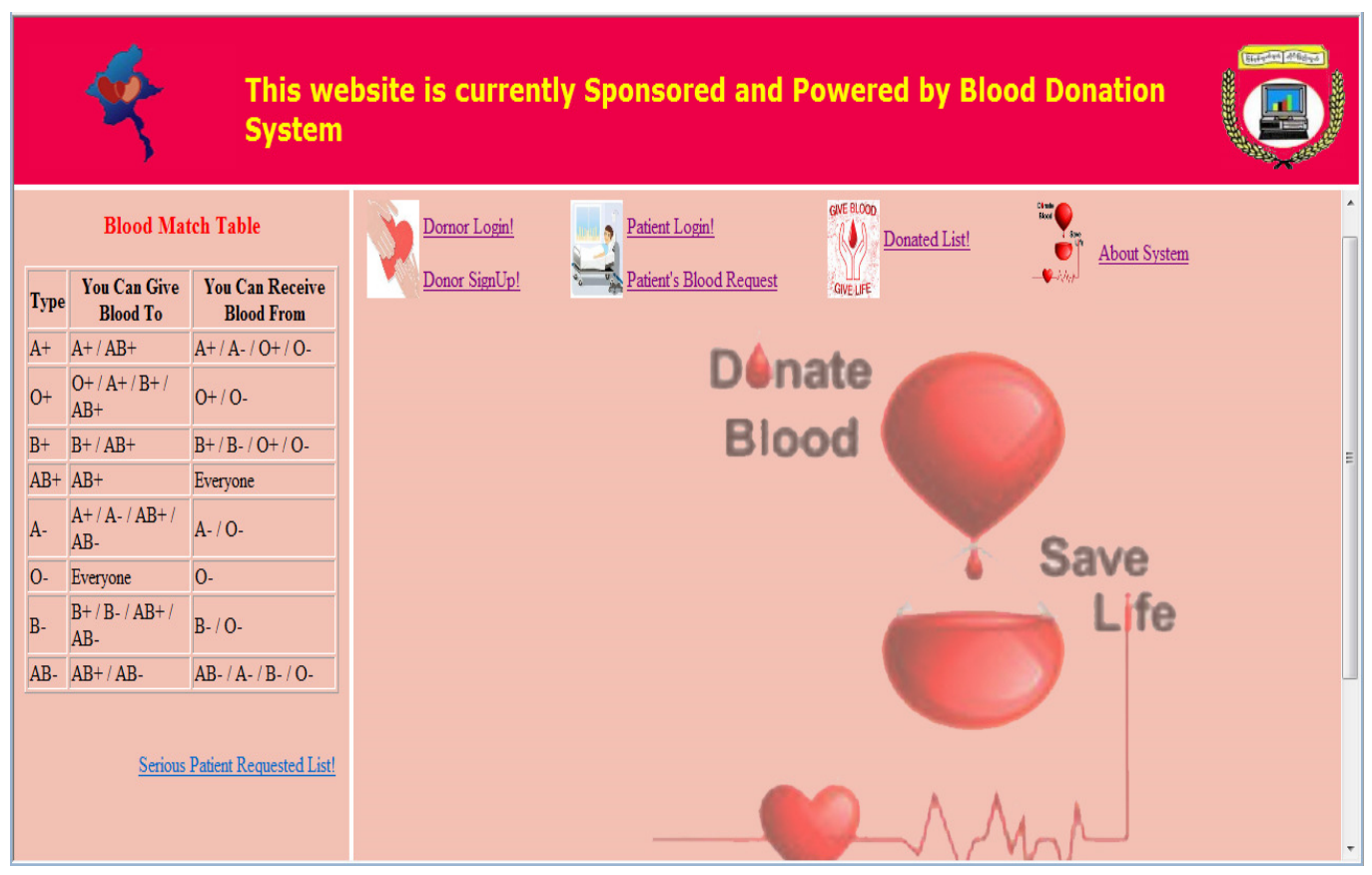

Figure 6. Home Page of the Blood Donation System

First of all, the system shows the home page Figure 6. The blood match table is shown on the left side of the page. And the right side of the page is included Donor Login!, Donor SignUp! for donors, Patient Login!, Patient Blood Request for patients, Donated List! , Home and About System for all. 


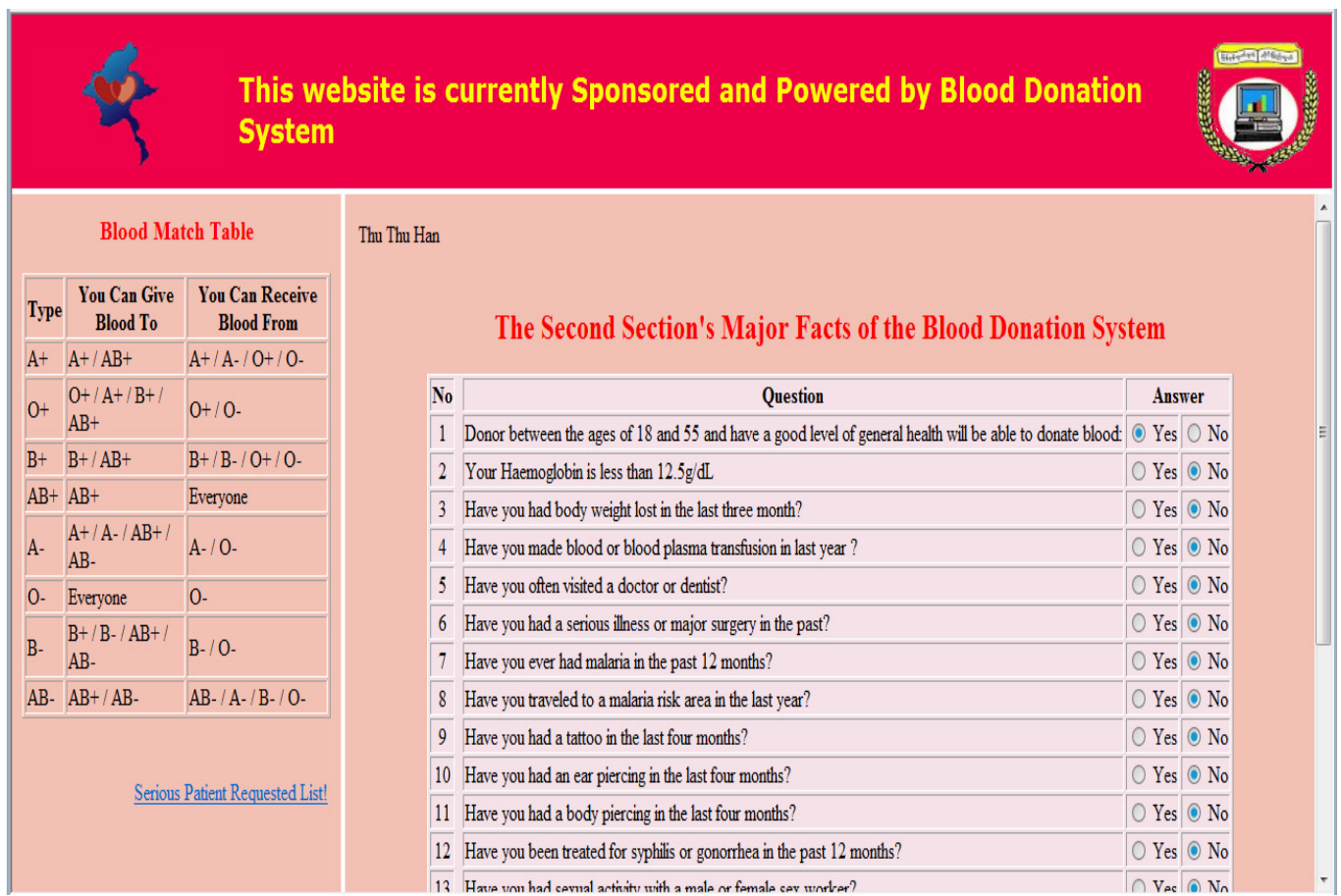

Figure 7 (a). Major Facts Page

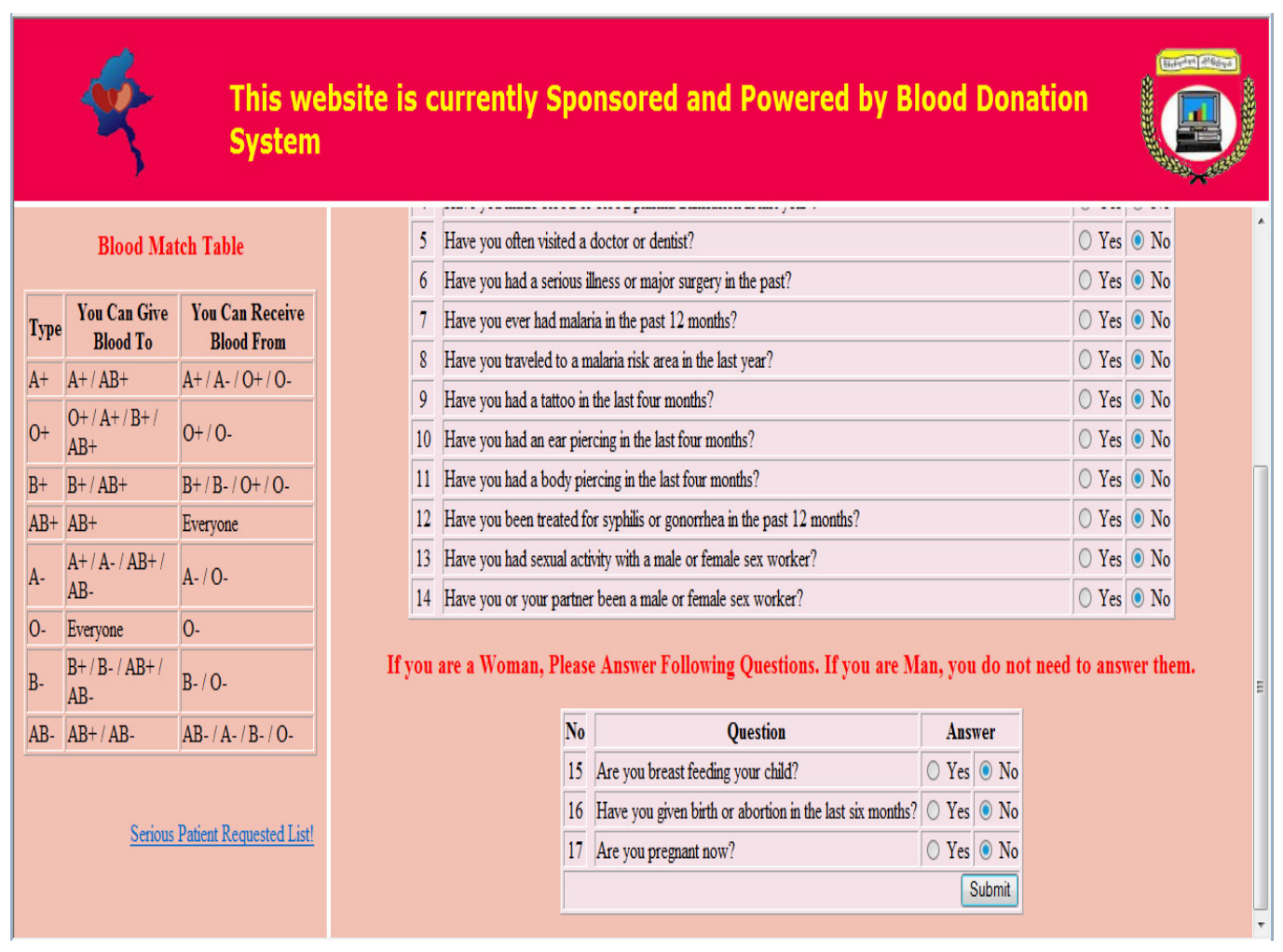

Figure 7(b). Major Facts Page with Woman Sections 
The Major Facts acquisition woman case will be answered for blood donor is a woman. Therefore, the questions for the woman are no need to answer for a man. But a man who is a blood donor makes a mistake that he fills the questions for the woman blood donor. Then the system automatically understands and these answers will be taken as don't care condition and operate the acquisition action as shown in Figure 7(a) and 7 (b).

\section{Conclusion}

This system provides communication between the Blood Donors and Patients compatibly. Webbased matcher draws up acceptable Blood Donors information for Patient by using Knowledgebased Rules. Moreover, the Web-based system provides more suitable application for health care and life saving processes. This system can be extended to other welfare societies and health organizations.

\section{Acknowledgements}

Our heartfelt thanks go to all people, who support us at the University of Computer Studies, Mandalay, Myanmar. This paper is dedicated to our parents. Our special thanks go to all respectable persons who support for valuable suggestion in this paper.

\section{References}

[1] W. Duch, " Rule-Based Methods ,Department of Informatics", Nicolaus Copernicus University, Poland, School of Computer Engineering, Nanyang Technological University, Singapore wduch@is.umk.pl.

[2] Lecture 2 "Rule-based Expert Systems", Negnevitsky, Person Education, 2002.

[3] D. Partridge and K. M. Hussain, "Knowledge Based Information Systems", Mc-Graw Hill, 1994.

[4] S. R. Safavian and D. Landgrebe, "A Survey of Decision Tree Classifier Methodology", School of Electrical Engineering Purdue University, West Lafayette, landgreb@ecn.purdue.edu.

[5] M. Verhelst, and De praktijk, "van beslissingstabellen. Deventer and Antwerp", Kluwer, 1980.

[6] J. Vanthienen, "Automatiseringsaspecten van de specificatie, constructie en manipulatie van beslissingstabellen", Katholieke Universiteit Leuven, Departement Toegeapste Economische Wetenschappen, Ph.D. thesis, 1986.

[7] J. Vanthienen, and G. Wets, "From decision tables to expert system shells ", Data \& Knowledge Engineering, 13, 265-282, 1994.

\section{Authors}

She is Associate Professor, Head of Department of Research and Development II in University of Computer Studies, Mandalay, Myanmar. Her research areas include Information Retrieval, Cryptography and Network Security, Web Mining and Networking. She received her B. Sc. (Physics), M.Sc.(Physics) from Yangon University, Myanmar and M.A.Sc.(Computer Engineering) and Ph.D.( Information Technology) from University of Computer Studies, Yangon, Myanmar.

Author studied computer science at the University of Computer Studies, lasho, Myanmar where she received her B.C.Sc Degree in 2011. She received B.C.Sc(Hons:) in computer science from the University of Computer Studies, Lasho, Myanmar in 2012. Since 2012, Au thor has studied computer science at the University of Computer Studies, Mandalay, Myanmar where her primary interests include web mining, graph clustering, grouping and web log analysis.
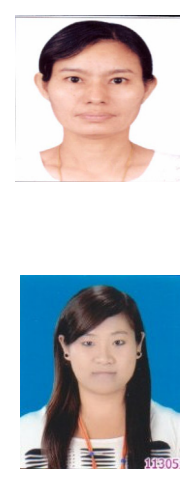